\title{
Bilateral Subcutaneous Patellar Calcifications and Unilateral Bursitis in Scleroderma
}

SYLVAIN MATHIEU, MD; MARTIN SOUBRIER, PhD; JEAN-JACQUES DUBOST, MD, Rheumatology Department, Gabriel Montpied Hospital, 63003 Clermont-Ferrand, France. Address correspondence to Dr. S. Mathieu; E-mail: smathieu11@yahoo.fr. J Rheumatol 2010;1060-1; doi:10.3899/jrheum.091335

A 59-year-old man with limited cutaneous systemic sclerosis $(\mathrm{lcSSc})$, who had retired after many years as a construction worker, presented with bilateral knee deformity without discomfort or pain. A diagnosis of lcSSc had been made 13 years previously on the basis of sclerodactyly, digital ulceration, calcinosis, and positive anticentromere antibodies. Treatment by ilomedine was initiated in 1999 because of severe Raynaud's phenomenon. In 1999, radiographs of the hands revealed multiple, bilateral calcifications. In 2009 he was referred for bilateral knee deformity without functional difficulties or pain. He had bilateral knee swelling without signs of local inflammation. There was no limitation in the range of joint movement. Radiographs of the knees showed dense bursitis in the left knee (Figure 1) and bilateral multiple subcutaneous calcifications ventral to the patellar and the tibial plateau projecting under the patellar (Figure 2). The characteristics of these calcifications were the result of the lcSSc. There have been only a few reports of such prepatellar bursitis with subcutaneous calcifications in scleroderma but there was often involvement, as in our patient, of a mechanical contributing factor ${ }^{1-3}$. We looked at knee radiographs from 2002, which already showed bursitis and subcutaneous prepatellar calcinosis. After a followup of 7 years, the patient reported knee deformity and blemish but no pain or symptoms.

There is no standard treatment for symptomatic knee calcifications in scleroderma but this case is a reminder that none is necessary for asymptomatic prepatellar calcinosis and bursitis in lcSSc because of its slow and well tolerated development.

\section{REFERENCES}

1. Cardon T, Cortet B, Deprez X, Flipo RM, Duquesnoy B, Delcambre B. Prepatellar acute calcifying periarthritis disclosing CREST syndrome. Rev Rhum Ed Fr 1993;60:474-5.

2. Delboy T, Marsaudon E, Allais C, Barrault MF. [Des calcifications d'un genou]. Calcifications of the knee. Rev Med Interne 1997;18:255-6.

3. Kamper L, Haage P. Images in clinical medicine. Infrapatellar [corrected] bursitis. N Engl J Med 2008;359:2366.

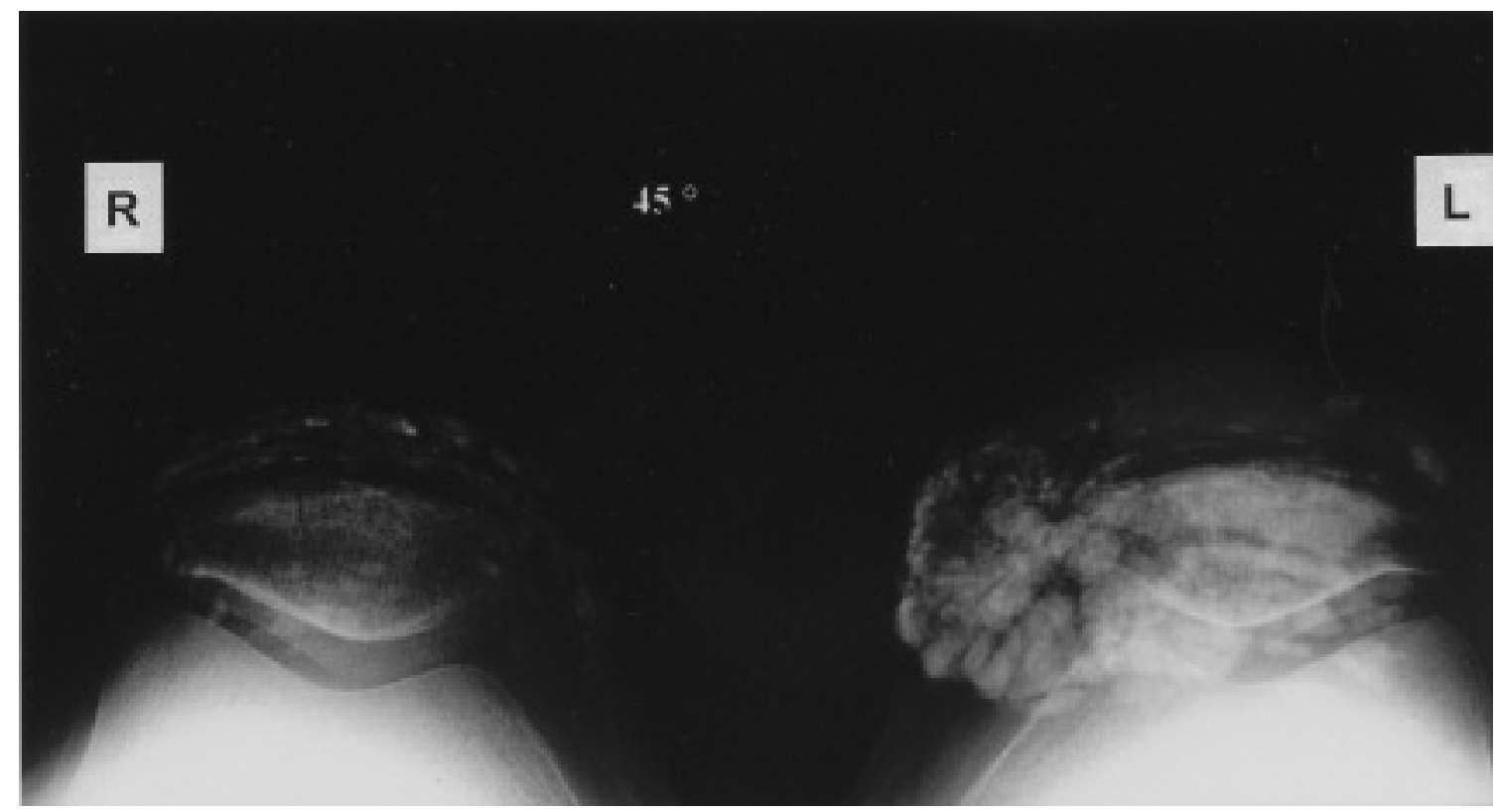

Figure 1. Radiographs of the knees showing dense bursitis in the left knee. Femoropatellar view.

Personal non-commercial use only. The Journal of Rheumatology Copyright @ 2010 . All rights reserved. 


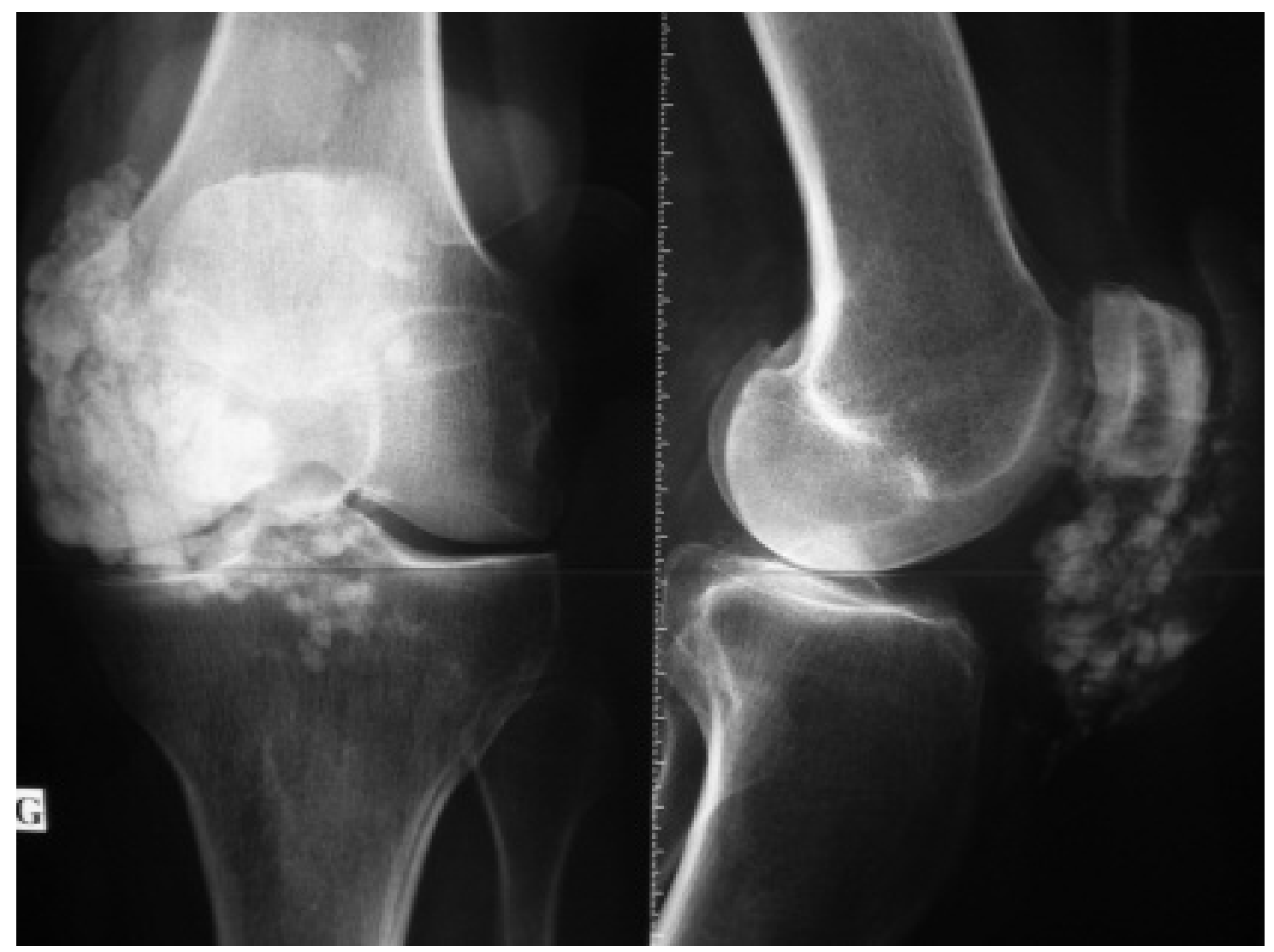

Figure 2. Radiographs of the left knee showing multiple subcutaneous calcifications. Anteroposterior view on the left and lateral view on the right. 